\title{
BEYOND STUDENT PERCEPTIONS: ISSUES OF INTERACTION, PRESENCE, AND PERFORMANCE IN AN ONLINE COURSE
}

\author{
Anthony G. Picciano \\ Professor, School of Education \\ Hunter College of the City University of New York \\ 695 Park Avenue, New York, NY 10021 \\ E-mail: apiccian@shiva.hunter.cuny.edu
}

\begin{abstract}
The research literature on Web-based learning supports the assumption that interaction is important for a successful course, yet questions exist regarding the nature and extent of the interaction and its effects on student performance. Much of the research is based on student perceptions of the quality and quantity of their interactions and how much they have learned in an online course. The purpose of this study is to examine performance in an online course in relationship to student interaction and sense of presence in the course. Data on multiple independent (measures of interaction and presence) and dependent (measures of performance) variables were collected and subjected to analysis. An attempt was made to go beyond typical institutional performance measures such as grades and withdrawal rates and to examine measures specifically related to course objectives.
\end{abstract}

\section{KEYWORDS}

Distance learning, Interaction, Presence, Social presence, Learning effectiveness, Outcomes, Student performance, Asynchronous learning, Computer-mediated learning, Computer-mediated communications, Education administration

\section{INTRODUCTION}

As access to the Internet and World Wide Web has continued to grow, Web-based learning has continued to expand. With approximately half of the households in the United States (or 150 million people connected to the Internet), an estimated 2 million students are taking post-secondary courses that are fully delivered online [1]. Millions of other students at all educational levels (primary, secondary, postsecondary, continuing education) participate online in hybrid, mixed mode, and Web-enhanced face-toface courses. However, the effectiveness of online courses particularly in relation to individual student needs, perceptions, and student-outcome is sometimes questioned [2], [3].

A common element for learning in a typical classroom environment is the social and communicative interactions between student and teacher, and student and student [4]. The ability to ask a question, to share an opinion with a fellow student, or to disagree with the point of view in a reading assignment are all fundamental learning activities. Web-based learning requires adjustments on the part of students and teachers for successful interactions to occur. Many online courses provide students and faculty, and students and students the ability to interact with each other via an electronic bulletin board, discussion board, email, or synchronous chat areas. The success of these courses frequently depends upon the nature of this interaction. It is not unusual for instructors to encourage, and in some cases require a certain 
amount of participation in the form of postings per week in online discussions as part of the grade for the course [5]. The research literature on Web-based learning supports this approach. Yet issues exist regarding the nature and extent of the interaction and its effects on student performance.

In examinations of interaction, the concept of "presence" or a sense of being in a place and belonging to a group also has received attention. A student's physical presence in a face-to-face course assumes that she or he has a sense of belonging to the class or group of students enrolled in the course. He or she listens to the discussion and may chose to raise a hand to comment, to answer or to ask a question. Furthermore, this same student may develop a relationship with other students in the class and discuss topics related to the class during a break, at the water fountain, or in the cafeteria. However, this is an assumption and not always true. For a variety of reasons, some students can also feel alienated in a face-to-face class and not feel part of a group. Presence in an online course has been the subject of a number of articles redefining and categorizing this concept. In an online course, the simplest definition of presence refers to a student's sense of being in and belonging in a course and the ability to interact with other students and an instructor although physical contact is not available. However, as this concept is studied, the definition is expanding and being refined to include telepresence, cognitive presence, social presence, teaching presence, and other forms of presence. The term "community" is related to presence and refers to a group of individuals who belong to a social unit such as students in a class. In an online course, terms such as communities of inquiry, communities of learners, and knowledge-building communities have evolved.

As the definition of presence has expanded and evolved, a distinction is being made between interaction and presence, emphasizing that they are not the same. Interaction may indicate presence but it is also possible for a student to interact by posting a message on an electronic bulletin board while not necessarily feeling that she or he is a part of a group or a class. If they are different, then it is also possible that interaction and presence can affect student performance independently.

Student performance is open to many definitions. Successful completion of a course, course withdrawals, grades, added knowledge, and skill building are some of the ways that performance is measured, depending upon the content of the course and the nature of the students. Courses may also have multiple performance outcomes, each of which might be measured separately through testing, written assignments, or the completion of individual and group projects. Many studies of student performance in face-to-face and online courses rely on student perceptions of their learning experiences including "how well" or "how much" they have learned. Ultimately, student perceptions of their learning may be as good as other measures because these perceptions may be the catalysts for continuing to pursue coursework and other learning opportunities. Student performance is well understood to be a multivariable phenomenon effected by study habits, prior knowledge, communications skills, time available for study, teacher effectiveness, etc. The purpose of this study is to examine performance in an online course in terms of student interaction and sense of presence. Data on multiple independent (measures of interaction and presence) and dependent (measures of performance) variables were collected and subjected to analysis.

\section{REVIEW OF THE LITERATURE}

The research literature regarding the importance of interaction in education especially in Web-based distance learning is extensive. There have been a number of studies and opinion papers on the relationship of interaction to learning. Many observers and researchers including this author have supported the concept that student to faculty and student to student interactions are important elements in the design of a Web-based course [4], [6], [7], [8], [9], [10], [11], [12]. Both students and faculty typically report increased satisfaction in online courses depending on the quality and quantity of interactions. For example, Shea, Fredericksen, Pickett, Pelz, and Swan in a survey of 3,800 students enrolled in 264 
courses through the SUNY Learning Network (SLN), conclude that the relationship of satisfaction, interaction, and performance (grades) was as follows:

The greater the percentage of the course grade that was based on discussion, the more satisfied the students were, the more they thought they learned from the course, and the more interaction they thought they had with the instructor and with their peers. [13]

Hartman and Truman-Davis in a survey of faculty teaching online courses found "statistically significant correlations (Amount of Interaction $-r=.726$; Quality of Interaction $-r=.807$ )" and concluded that the interaction was critical to faculty satisfaction [14].

Dziuban and Moskal, in a paper entitled Emerging Research Issues in Distributed Learning, likewise report very high correlations and relationships between interaction in online courses and student satisfaction [15]. Their conclusions are based on a questionnaire $(\mathrm{N}=52,218)$ collected by the Research Initiative for Teaching Effectiveness at the University of Central Florida over a three-year period, from students enrolled in Web-based (fully online) courses, mixed-mode (some online, some face-to-face) courses, and Web-enhanced, face-to-face courses. Among their findings were statistically significant correlations between the quantity and quality of the interaction and student satisfaction in all three types of courses. However, in Web-based courses, the relationship of interaction to perceived success appears a more critical factor than in the other (mixed-mode or Web-enhanced) courses. They recommend that more research was needed specifically on the question: What is the impact of class interaction in Webbased courses?

While most of the research supports the relationship of interaction and satisfaction in Web-based courses, some observers have cautioned that this is not always the case. Ruberg, Taylor, and Moore, for example, observes that in order to interact successfully, students must adjust to the non-linear, asynchronous nature of Web-based learning [16]. Typical face-to-face situations tend to be linear, focusing on a single discussion thread. Asynchronous, Web-based learning sessions on an electronic bulletin board can have multiple threads with several discussions and interactions progressing simultaneously. Students respond to the teacher but also to other students, depending on their interest and points of view. Students can initiate a new discussion as easily as the teacher. Sproull and Kiesler caution about discussions that continue based on misinformation because in asynchronous mode an instructor cannot immediately correct or clarify a comment [17]. As a result, students need to have the experience and knowledge base to sift the discussion for misinformation. In asynchronous learning, the amount of student interaction and the number of comments can easily lead to what Mackay described as information overload [18]. Furthermore, comments in on-line discussions tend to be lengthier than in face-to-face situations. With more information from many sources, students need to be more attentive to both the who and what of a discussion. Herbert Simon, economist and Nobel Prize laureate, succinctly cautions, "a wealth of information can create a poverty of attention" [19].

Michael Beaudoin in a paper entitled, Learning or Lurking? Tracking the 'Invisible' Online Student, examines the relationship between student interaction and learning [20]. In the study, he divides an online class into three groups (high interaction, moderate interaction, and low interaction). He reveals that while the high interaction students achieved the highest performance, the low interaction group performed higher than did the moderate interaction group. Most faculty have probably observed similar situations in many classes. While much of the research relates student satisfaction and performance to the active participation in online course activities, faculty teaching these courses face a small dilemma in establishing requirements for interacting online because some students may not need to participate 
actively in the course to do well on a test or some other performance measure.

Related to the research on interaction is the concept of presence. Students who feel that they are part of a group or "present" in a community will, in fact, wish to participate actively in group and community activities. Presence has a social psychology basis related to how individuals respond and interact using different forms of media [21], [22]. In one of the most extensive recent reviews of the literature on the subject, Lombard and Ditton define presence as the perceptual "illusion of nonmediation" [23]. An "illusion of nonmediation" occurs when a person fails to perceive or acknowledge the existence of a medium in his/her communication environment and responds as he/she would if the medium were not there. Furthermore, because it is a perception, presence can and does vary from individual to individual. It can also be situational and vary across time for the same individual, making it a complex subject for research. While the literature on presence has existed for a number of years, Lombard and Ditton concluded that the "research on presence was in its infancy" [23]. Specifically, little was known about the "characteristics of a medium's form and content," "the characteristics of medium users that encourage a sense of presence," and "the effects of presence once it is evoked." These critics recommend that research on presence be conducted within the specific context of a medium and within six categories, which they refer to as conceptualizations.

Researchers studying applications related to virtual reality software, computer-mediated communications, and online learning increasingly are redefining our understanding of presence in light of the ability of individuals to communicate extensively in a group via digital communications networks. The term "telepresence" has evolved and has become popular as an area of study [24], [25], [26]. Tammelin especially establishes a relationship between telepresence and social presence as one (telepresence), leading to the other (social presence) [24]. Biocca classifies presence into three types: spatial presence, self-reflective presence and social presence [27]. Rourke, Anderson, Garrison, \& Archer with respect to online learning environments provided a community of inquiry model with three presence components: cognitive, social, and teaching [28]. While recognizing the overlap and relationship among the three components, Rourke and others advise research on each of these individual components [28]. Their model supports the design of online courses as active learning environments or communities dependent on instructors and students sharing ideas, information, and opinions. What is critical here is that presence in an online course is fundamentally a social phenomenon and manifests itself through interactions among students and instructors. Rourke and co-researchers recommend teaching strategies to foster presence, which will be discussed later on in the section on Methodology [28].

Interaction and presence in a an online course can be studied for many reasons including vibrancy of a discussion, students willingness to share ideas, participation in collaborative activities, and group projects, all of which can support productive learning environments. Ultimately, however, student performance outcomes need to be evaluated to determine the overall success of a course. An extensive amount of literature exists on performance outcomes as related to distance learning. Keegan comments that measuring student success is a "preoccupation" in distance learning especially where adults were concerned [29]. While much work has been done in this area, student outcomes are not easy to define in higher education; even experienced researchers have characterized them as "messy" [15]. For example, while grades and their derivatives such as grade point averages are common student performance measures, they can be problematic particularly in light of concerns about issues such as grade inflation. At Harvard University, for example, the Boston Globe reported that "48.5 percent of the grades last year [2000] were A's and A-minuses, ...B grades were 45 percent.... Grades in the three $\mathrm{C}$ categories [were] 4.9 percent... D's and failing grades accounted for less than 1 percent each" [30]. Susan Pedersen, Harvard's dean of undergraduate education, commented that with such a narrow range of effective grades available [essentially, B, B+, A-, and A], faculty find it difficult to distinguish adequately between work 
of differing quality [30].

Course completion and attrition rates are considered to be important student performance measures especially as related to adult and distance learning [25], [31], [2], [11]. Moore and Kearsley have reported student attrition rates as high as 50 percent in some distance learning programs [25]. However, attrition is a complex phenomenon dependent on a myriad of academic, social, and personal factors including the academic program (graduate, undergraduate, continuing education), admissions criteria (selective, open admissions), and the nature of the student (mature, motivated, command of basic skills).

The literature on quality issues in distance learning suggests that multiple measures related to individual academic program and course objectives should be used in studying student performance [3], [31], [13], [15]. Performance data can be in the form of tests, written assignments, projects, and satisfaction surveys. For the purposes of this research, this multiple measure approach is respected and utilized. Data on student perceptions of their learning as well as other actual measures specifically related to course objectives are collected and analyzed below.

In summary, a good deal of research has been conducted on interaction, presence and student performance in Web-based learning. While researchers can draw from the past for insight, new situations created through new technology require new study and evaluation. As educators attempt to develop and implement these technologies in instruction, on-going evaluation and study involving multiple measures will be necessary.

\section{RESEARCH QUESTIONS}

The major research questions that guided this study are as follows:

1. What is the relationship between actual student interaction/participation and performance?

2. What is the relationship between student perception of social presence and performance?

3. What is the relationship between student perceptions of social presence and actual participation?

4. Are there differences in student perceptions of their learning experiences and actual performance?

5. Are there differences in student perceptions of their interaction and actual participation?

For purposes of this study, presence was defined as an "illusion of nonmediation" which occurs when a person fails to perceive the existence of a medium in his/her communication environment [23]. Furthermore, the social component of this definition refers to a student's sense of belonging in a course or group and the ability to interact with others, although physical contact is not available.

\section{METHODOLOGY}

\section{A. Program/Course}

The methodology used for this study was a descriptive analysis of interaction, presence, and performance data collected in a graduate course in an education administration program at Hunter College in New 
York City. The Education Administration and Supervision Program at Hunter College is a thirty-credit graduate program leading to New York State certification as a school administrator. New York State requires a minimum of eighteen graduate credits plus an internship. The program at Hunter requires twenty-four credits (eight courses) plus a six-credit internship. Web-based courses have been offered in this program since 1997, and students can complete a majority of the coursework for the program online. For the past ten years, the program has maintained an enrollment of 100 to 125 students, almost all parttime. Because of funding and a desire to insure academic quality, the enrollment in the program has been limited.

The course entitled, Administration and Supervision (ADSUP) 722 - Issues in Contemporary Education, is an elective course. This course is designed to provide a forum for the presentation and discussion of issues in contemporary education. It also is designed to provide future administrators with an appreciation of differences in points of view and the ability to approach issues that can be divisive in a school or community. Thirteen contemporary issues in education such as charter schools, teacher unionization, bilingual education, and special education form the content of the course. The course is structured around readings and a weekly discussion. In addition, written assignments are required which are designed to put the student in the position of an administrator making a decision or recommending a course of action related to one of the issues.

\section{B. Students}

To enroll in the graduate program in Education Administration and Supervision at Hunter College, all students must have at least five years teaching experience and an earned MA. All of the students are education professionals already certified as teachers by New York State, who are seeking further certification as school administrators. More than $80 \%$ are women. Approximately $25 \%$ are students from minority groups. Approximately $75 \%$ percent of these students work in New York City public schools, while the remaining $25 \%$ work in private schools or in public schools outside of New York City. The students in this program recognize the importance of technology, and the vast majority of the enrollees have access to computer and Internet technology in their homes. Many are also professionally curious about an alternative pedagogical experience, such as Web-based learning using the Internet and other current technological tools.

All of the students balance full-time jobs, families, parenthood, and higher education in a carefully planned day, which includes rushing for subways and buses to meet the next commitment. They are a mature group who organize their daily lives around lesson plans, making sure their children get to the babysitter or day care center, maintaining a home, and when time permits, completing homework assignments. Courses that can be taken at anytime or in anyplace have a good deal of appeal. These students are able to fit their graduate studies into their busy lives, eliminating the need to travel several times per week to the College. These students typify the mature, self-directed, and busy "students" who could take advantage of and benefit from this form of instruction.

From the group described above, twenty-three (N=23) students enrolled in ADSUP 722 for Fall 2001. Their average age was thirty-seven years. Sixteen were female and seven were male. The ethnic composition was as follows: three African-American, three Latino, and seventeen White/Caucasian. Eight of the twenty-three students had previously taken an online course(s); the remaining fifteen had not.

\section{Instructional Components}

A completely asynchronous model was used for delivering this course via a course Web site utilizing the 
BlackBoard course management system (CMS). To connect to the course Web site, most students used a commercial Internet and e-mail provider such as America On-line or Compuserve in their homes. Several students also used Internet facilities available in their schools.

The course was organized into thirteen weekly themes and topics. The Web site for the course included a syllabus, reading assignments, weekly discussion topics and questions, supplementary reading material, and related links. These materials were always available and served as the organizational anchors for the course. Each topic was organized for an asynchronous discussion on an electronic discussion board during a specific week and was based on assigned readings and case studies. Four students were selected each week to work with the instructor as discussion facilitators. The use of students as facilitators was designed to encourage them to be contributors to and not simply receivers of learning activities. Once the discussion of a topic commenced on Sunday morning, any student could contribute to the discussion, ask a question of another student or the instructor. At the end of the week's discussion on the following Saturday, the instructor summarized the topic, added additional notes and comments, and posted these to the Web site for access by the entire class.

Techniques to encourage social presence and a sense of community were used throughout the course. Rourke and others provide an excellent review of some of the techniques that can be used to foster a sense of presence and community building including: complimenting students, self-disclosure, warmth, and activities that build and sustain a sense of group commitment [28]. In this course, many of these techniques were used. For example, first names were used in all online discussions. Discussion questions were designed to encourage students to relate the material to their experiences in their own schools and environments. Students were used as facilitators each week to encourage them to assume some ownership of the online discussion and to reduce - but not eliminate - dependence on the instructor. An internet cafe where students could interact on non-instructional issues was also available. This facility was used, for instance, for comments and discussions during the terrorist attack on the World Trade Center on September 11th during the second week of our course, as well as at the time of the birth of a daughter to one of our students during the eighth week of the course.

It is accepted that the instructional model presented above for an online course is highly dependent upon faculty-to-student and student-to-student interactions via electronic discussions. As a result, the findings may only relate to similar instructional models. Other online course models using intelligent software tutoring or programmed instruction techniques that are dependent upon far fewer person-to personinteractions may have different issues requiring study methodologies not provided for here.

\section{Data Collection and Analysis}

The purpose of this study was to examine performance in an online course in relationship to student interaction and a sense of presence in the course. Data on multiple independent (measures of interaction and presence) and dependent (measures of performance) variables were collected and subjected to analysis.

Data on actual student participation in online discussions were collected throughout the semester. Students also completed a satisfaction survey (see Appendix) at the end of the course, which asked a series of questions addressing their overall experiences, especially as related to their learning and interaction with others and the technology used. A series of questions (Questions 16A through 16K) relate to social presence was included as part of this survey. These questions are based on the Inventory of Presence Questionnaire developed by the Presence Research Working Group (http://www.presenceresearch.org) at the Technische Universiteit Eindhoven, Netherlands and on a questionnaire developed by 
Chih-Hsiung Tu [32].

In addition to student perceptions of their learning as collected on the student satisfaction survey, two student performance measures are collected: scores on an examination and scores on a written assignment. The latter measures relate to the course's two main objectives: to develop and add to the student's knowledge base regarding contemporary issues in education, as well as to provide future administrators with an appreciation of differences in points of view and an ability to approach issues that can be divisive in a school or community. The examination was designed to assess knowledge of the course subject matter and was based on the thirteen issues explored during the semester. An objective, multiple choice question and answer format was used. The written assignment was a case study that required the students to put themselves in the position of a newly appointed principal who has to consider implementing a new, controversial academic program. For purposes of this study, this assignment was graded by an independent scorer who used content analysis techniques to identify phrases and concepts to determine student abilities to integrate multiple perspectives and differing points of view in deciding whether and how to implement the academic program. These performance measures corresponded specifically to the objectives of the course as established by the instructor. Other performance measures such as grades were not used because of the difficulty to distinguish adequately between student work of differing quality where letter grades (A, B, C) are used. In addition, student participation or interaction was included as part of the overall grading criteria, bringing into question the use of these grades in relationship to interaction. Withdrawal or attrition data also were not a factor in this study since all of the students completed the course. This is not unusual for graduate programs with selective admissions requirements.

Because of the small sample size of the student population, no attempt is made to use formal statistical significance or sample size techniques to infer that the results of this study represented larger populations. Instead basic descriptive analyses using means and correlations are used.

\section{RESULTS}

\section{A. Student Perceptions of Interaction and Learning}

To determine the relationship between student perceptions of their interaction and performance, the student satisfaction survey contains questions about each of these. Questions 9A through 9D (see Appendix) compares the amount and quality of their interactions with students and the instructor compared to traditional courses. Responses were formatted in a Likert scale with values ranging from 15 (Decreased - Somewhat Decreased - No Change - Somewhat Increased - Increased). The responses to these questions are scored and combined into an overall perception of student interaction variable that ranged from 1 to 5 . The mean for all students on this perception of interaction variable was 4.00 (Somewhat Increased).

Questions 9E and 9F (see Appendix) on the student satisfaction survey refer to the quality and quantity of their learning experiences. Responses were formatted in a Likert scale in the same way as the interaction questions. The responses to these questions are scored and combined into an overall perception of student learning variable that ranged from 1 to 5 . The mean for all students on this perception of learning variable was 4.32 (Somewhat Increased, plus). Performing a simple correlation on these two variables, the resulting coefficient is positive (.6732), as well as statistically significant (.05 level).

These results indicated that there is a strong, positive relationship between student perceptions of their interaction in the course and their perceptions of the quality and quantity of their learning. These results 
are similar to other studies conducted on larger populations [13] [15].

\section{B. Actual Student Interaction and Performance}

Throughout the semester, data were collected on the actual number of student postings to the discussion board (see Figures 1 and 2). The postings included in this count were substantive comments or questions made to the discussion board and excluded one line "me too" postings and social messages. The total number of postings of individual students for the semester ranged from a low of 9 to a high of 101 with a mean of 42.26 or approximately 3 postings per student per week. Students were not required to make a particular number of postings to the discussion board each week. However, students were informed that part of the grade for the course would be based on their participation in these discussions.

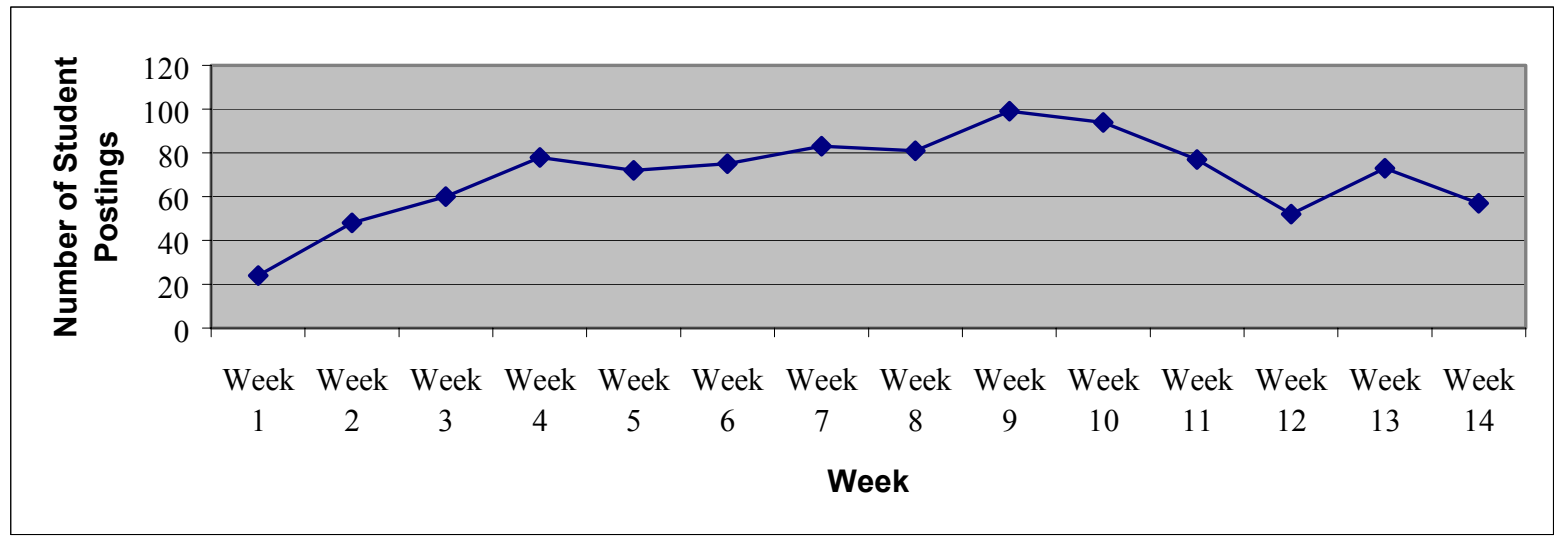

Figure 1. Total Student Postings Per Week

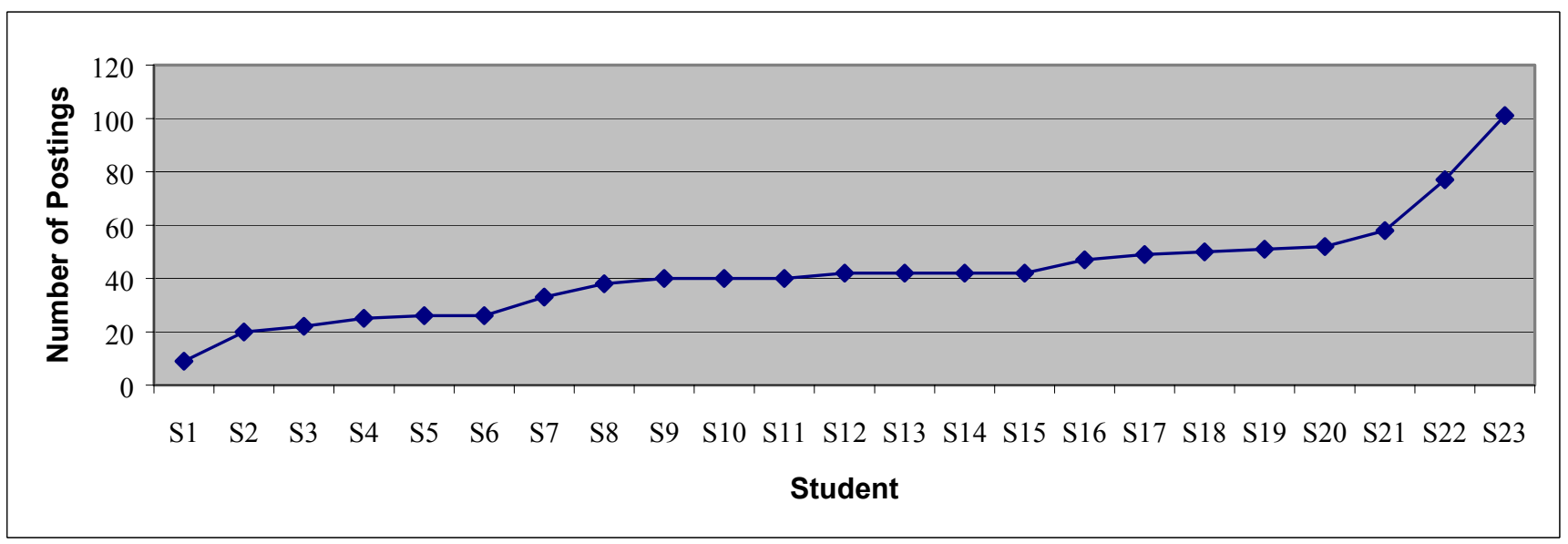

Figure 2. Total Postings Per Student

Student postings constituted one indicator for actual participation in the course since it showed the number of times students read and responded in writing to the instructor's or to another student's posting. In performing a correlation on actual student postings with actual student performance scores on the examination and written assignment, the results were positive at .1318 and .4577 but not statistically significant (.05 level). While positive, these correlations especially on the exam were somewhat weaker than the coefficient (.6732) for student perceptions of their interaction and their learning presented in Section A above. 
In pursuing the relationship between actual interaction and student scores on the examination and the written assignment, the data on interaction were sorted by the number of student postings and divided into thirds representing low interaction, moderate interaction, and high interaction student groups. Mean scores on the exam and on the paper were then calculated for each group (see Table 1).

Table 1. Mean Student Scores on Exam and Written Assignment Controlling for Interaction Group (N=23)

\begin{tabular}{ccc} 
Interaction Group & $\begin{array}{c}\text { Mean } \\
\text { Exam Score }\end{array}$ & $\begin{array}{c}\text { Mean } \\
\text { Written Assignment Score }\end{array}$ \\
\hline Low & 85.0 & 63.7 \\
Moderate & 85.7 & 64.4 \\
High & 85.6 & 81.1
\end{tabular}

Note: Overall Mean for All Students on the Exam $=85.4$

Overall Mean for All Students on the Written Assignment $=70.0$

The data in Table 1 indicate that there were no differences among the three interaction groups in terms of actual performance on the examination. On the written assignment, the high interaction group scored significantly higher than the low and moderate interaction groups. The overall conclusion was that actual student interaction as measured by the number of postings on the discussion board had no relationship to performance on the examination. Actual student interaction as measured by the number of postings on the discussion board did have a relationship to the written assignment for students in the high interactive grouping.

\section{Social Presence and Performance}

To collect data on the students' perceptions of social presence, a series of questions (Questions 16A through $16 \mathrm{~K}$ ) related to presence was included as part of the student satisfaction survey completed at the end of the semester. Responses were formatted in a Likert scale with values ranging from 1- 7 (Strongly Disagree - Somewhat Disagree - Disagree - No Opinion - Agree - Somewhat Agree - Strongly Agree). The responses to these questions were scored and combined into an overall perception of social presence variable that could range from a low of 7 (Strongly Disagree) to a high of 77 (Strongly Agree). The actual student scores ranged from a low of 48 to a high of 76 . The mean for all students on the perception of social presence variable was 64.26 (Somewhat Agree). The correlation between perception of social presence variable and the overall perception of student interaction variable discussed in Section A above was highly positive (.8477) and statistically significant (.05 Level), as one would expect. The correlation between perception of social presence variable and the overall perception of learning variable discussed in Section A above was also highly positive (.6714) and statistically significant (.05 Level). In sum, there is a definite, consistent and strong relationship among student perceptions of interaction, social presence, and learning.

In comparing student perceptions of social presence with actual performance measures, the results are somewhat different. The correlation between student perception of social presence and the written assignment was statistically significant (.05 Level) and positive (.5467); however, the correlation between student perception of social presence and the examination was inversed at (-.3570) and not statistically significant at the .05 level. 
In pursuing the relationship between student perception of social presence and student scores on the examination and written assignment, the data on social presence were sorted by the overall perception of social presence variable and divided into thirds representing low perception of social presence, moderate perception of social presence, and high perception of social presence groups. Mean scores on the exam and on the paper were then calculated for each group (see Table 2).

Table 2. Mean Student Scores on Exam and Written Assignment Controllingfor Social Presence (N=23)

\begin{tabular}{ccc} 
Social Presence & $\begin{array}{c}\text { Mean } \\
\text { Exam Score }\end{array}$ & $\begin{array}{c}\text { Mean } \\
\text { Written Assignment Score }\end{array}$ \\
\hline Low & 87.5 & 55.5 \\
Moderate & 87.5 & 70.1 \\
High & 80.0 & 80.0
\end{tabular}

Note: Overall Mean for All Students on the Exam $=85.4$

Overall Mean for All Students on the Written Assignment $=70.0$

The data in Table 2 indicate that while there is no difference between the low and moderate social presence groupings on the examination; there is a significant difference and a lower mean for the high social presence group compared to the other two groups. On the other hand, on the written assignment, the differences between the three groups supports the high correlation between student perception of social presence and performance on the written assignment with each group scoring progressively higher (55.5 -> 70.1 ->80.0).

The overall conclusion is that student perception of social presence did not have a statistically significant relationship to performance on the examination, while student perception of social presence had a positive, statistically significant relationship to performance on the written assignment.

\section{Student Perceptions of Interaction and Actual Participation}

The last area for analysis in this study was the relationship between the perceived interaction of students and actual interaction. In Section A, it was already reported that the mean for all students on the perception of interaction variable (collected on the student satisfaction survey) was 4.00 (Somewhat Increased). On the same survey, the question was asked: "On average, how often did you post a message to the Discussion Board each week?" Students reported making 2.9 postings per week, which resulted in a mean of 41.3 postings per student for the entire semester ( 2.9 postings per week x 14 weeks). The actual postings per student as collected week by week by the instructor resulted in a mean of 42.26 postings per student for the entire semester. The two means (41.3 and 42.26) are almost identical. A correlation analysis of perceived number of postings per student and the actual postings per student resulted in a positive (.5756) and statistically significant (.05 Level) correlation. One might have expected this correlation to be somewhat higher. In sorting the actual number of student postings into three groups (as was done in Section A) of low, moderate, and high and comparing them to perceived number of postings, some differences became apparent.

Table 3. Mean Number of Actual and Perceived Student Postings to the

Discussion Board for the Entire Semester Controlling for Interaction Group ( $\mathbf{N}=\mathbf{2 3})$ 


\begin{tabular}{lcc} 
Interaction Group & $\begin{array}{c}\text { Mean } \\
\text { Actual Postings }\end{array}$ & $\begin{array}{c}\text { Mean } \\
\text { Perceived Postings }\end{array}$ \\
\hline Low & 24.87 & 36.75 \\
Moderate & 41.14 & 38.00 \\
High & 60.62 & 49.00
\end{tabular}

Note: Overall Mean Number of Actual Postings $=42.26$

Overall Mean Number of Perceived/Reported Postings $=41.3$

The data in Table 3 indicate that while the perceptions of the number of postings of the moderate interaction group of students are consistent with their actual postings, the low interaction group perceived themselves to have made a higher number of postings than they actually did and the high interaction group perceived themselves to have made fewer postings than they actually did. The results indicate that student perceptions of their interaction in a course need to be viewed with a bit of caution.

\section{DISCUSSION}

\section{A. Interaction}

The results of this study support the findings in other research which establish a strong relationship between students' perceptions of the quality and quantity of their interaction and their perceived performance in an online course. However, in comparing student interaction as defined by actual postings on a discussion board to actual performance measures designed specifically to measure course objectives, the results are not consistent.

The data in Table 1 indicate that there were not differences among the three (low, moderate, high) interaction groups in terms of actual performance on the examination. This study did not attempt to answer the "why?" for this phenomenon, but speculation is possible. For instance, it is likely that all students, and especially the low interaction group, studied for the examination. The questions on the examination were derived mostly from the weekly discussions and instructor notes that were available on line. The low interaction students may have read much of the material posted during the weekly discussion but simply chose not to comment. This is not unlike a student in a regular face-to-face class who listens attentively but does not raise his or her hand, yet still does well on a test or exam.

On the written assignment, the high interaction group scored significantly higher than the low and moderate interaction groups, which scored about the same. The written assignment was based on a case study and designed to determine student's ability to integrate multiple perspectives and differing points of view in deciding whether and how to implement an academic program. The assignment was similar to situations presented on the weekly discussion board in that students were posting their comments and opinions on educational issues taking into consideration what already had been posted by their colleagues in the class. Hence, a relationship might exist for students who interact extensively on a discussion board and who are required to respond to similar situations such as that presented in the case study. On the other hand, students in the high interaction group may be especially sensitive to differing points of view. Whether these students already possessed these abilities and they were honed as part of the weekly discussion board activities is difficult to assess. 
To expand on the relationship between high interaction and high score on the written assignment, what might be at work is that the "everyone has a right to an opinion" format of an interactive, discussion board environment rewards a student's facility with ad hoc discussion. The written project required recognizing and including multiple perspectives rather than reflecting knowledge of objective content. Students may even perceive themselves as learning more but that doesn't necessarily mean they do learn more in these environments.

\section{B. Social Presence}

Student perception of social presence has a small inverse but not statistically significant relationship to performance on the examination, while student perception of social presence demonstrates a strong positive and statistically significant relationship to performance on the written assignment. Social presence in this class depended upon participation in the weekly discussions, which encouraged an appreciation for the points of view of others. It was in the weekly discussions that students could "socialize," identify with, learn something about the other students, and relate to the personal experiences of their colleagues, who were all educators. Those who felt the "presence" of their colleagues as a result of what was read and written on the discussion board perhaps could relate better to an activity such as the written assignment that was similar to the discussion board activity. On the other hand, their sense of "presence" possibly did not relate to an objective, multiple-choice examination because it was not an expressive activity but an asocial impersonal activity.

\section{CONCLUSION}

This study examined performance in an online course in relationship to student interaction and sense of presence in the course. An attempt was made to go beyond student perceptions of interaction and performance and to include perceptions of social presence as well as actual participation in class activities. In addition, data were collected on performance measures that related specifically to course objectives. Typical institutional performance measures such as grades and withdrawal rates were not included. While much of the research including this study, supports the strong relationship between students perception of interaction and perceived learning, the results of this study indicated that the relationship of actual measures of interaction and performance is mixed and inconsistent depending upon the measures.

The results of this study should not be interpreted to indicate that interaction is not a key course component in instructional design. To the contrary, by design, the success of many online courses is dependent upon the nature of student to student and student to faculty interaction. However, how interaction effects learning outcomes and what are the relationships between the two is a complex pedagogical phenomenon in need of further study. 


\section{APPENDIX}

\section{STUDENT EVALUATION OF ADSUP 722 - Fall 2001}

Name:

Date:

1. Number of Credits Completed in this Program:

2. Age:

3. Gender: Female Male

4. I would rate my level of computer expertise as: Novice___ Intermediate____ Expert

5. Where did you most frequently use a computer for this course?

Home___ Work___ Other___ If other, specify:

6. How easy/difficult was it for you to use technology to participate in this course?

Easy___ Somewhat Easy ___ Somewhat Difficult ___ Difficult

7. How would you rate your overall educational experience in taking this course?

Poor___ Satisfactory___ Good___ Very Good___Excellent

8. Would you take another Internet (asynchronous learning) course if offered?

No___ Maybe___ Definitely

For questions 9A through 9H, in comparison to traditional classroom instruction, in this course

$\begin{aligned} \text { Somewhat No Somewhat } & \text { Somed } \\ \text { Increased Increased Change } & \text { Decreased Decreased }\end{aligned}$

9A. The amount of interaction with other students

9B. The quality of interaction with other students

9C. The amount of interaction with the instructor

9D. The quality of interaction with the instructor

9E. The quantity of your learning experience

9F. The quality of your learning experience

9G. The motivation to participate in class activities 
9H. Your familiarity with computer technology

10A. On average, regardless of whether you posted a message or not, how often did you access the course Web site each week?
a. once a week
b. twice a week
c. three times a week
d. four times a week
e. five or more times a week

10B. On average, how often did you post a message to the Discussion Board each week?
a. once a week
b. twice a week
c. three times a week
d. four times a week
e. five or more times a week

11. Would you rate your experiences to date with this course as Successful Not Successful If successful, what aspect of the course most contributed to its success:

If not successful, what aspect of the course was most problematic:

12. Should the Hunter College ADSUP Program offer more internet (asynchronous learning) courses? Yes No

If yes, because:

If no, because: 
13. I have the following suggestions for improving this course:

14. To provide materials and to communicate online, a software system called BlackBoard was used. Can you please rate how easy/difficult it was for you to use the BlackBoard software.
Easy
Somewhat Easy
Somewhat Difficult
Difficult

15. During this course, you had several tools available to you at the Course Web site for accessing information and for communicating with colleagues and the instructor. Please rate the following:

\begin{tabular}{llcccc} 
& \multicolumn{3}{c}{ Somewhat Very } \\
Not & Important Important Important Critical & Impl \\
& Used & Tool & Tool & Tool & Tool
\end{tabular}

15A. Course Information

15B. Course Documents

15C. Weekly Summaries

15D. Discussion Board

15E. Online Library Resources

15F. Digital Drop Box

15G. Other

For questions $16 \mathrm{~A}$ through $16 \mathrm{~J}$, please circle the answer which best describes your opinion of the ADSUP 722 online course.

16A. I enjoyed the online course.

\begin{tabular}{|c|c|c|c|c|c|}
\hline Strongly & Somewhat & & No & Somewhat & \\
\hline Disagree & Disagree & Disagree & Opinion & Agree & Agree \\
\hline
\end{tabular}

16B. Even though we were not physically together in a traditional classroom, I still felt like I was part of a group in the online course.

\begin{tabular}{|c|c|c|c|c|c|}
\hline Strongly & Somewhat & & No & Somewhat & \\
\hline Disagree & Disagree & Disagree & Opinion & Agree & Agree \\
\hline
\end{tabular}

16C. The online course stimulated my desire to learn. 


\begin{tabular}{|c|c|c|c|c|c|}
\hline Strongly & Somewhat & & No & Somewhat & \\
\hline Disagree & Disagree & Disagree & Opinion & Agree & Agree \\
\hline
\end{tabular}

16D. An online course provides a personal experience similar to the classroom.

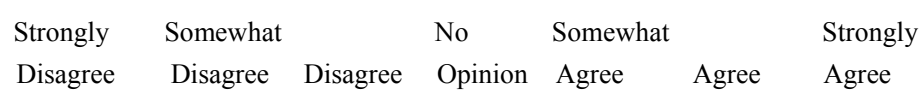

16E. An online course allows for social interaction.

\begin{tabular}{|c|c|c|c|c|c|}
\hline Strongly & Somewhat & & No & Somewhat & \\
\hline Disagree & Disagree & Disagree & Opinion & Agree & Agree \\
\hline
\end{tabular}

16F. An online course allows me to express my feelings, and to learn the feelings of others.

\begin{tabular}{|c|c|c|c|c|c|}
\hline Strongly & Somewhat & & No & Somewhat & \\
\hline Disagree & Disagree & Disagree & Opinion & Agree & Agree \\
\hline
\end{tabular}

16G. An online course provides a reliable means of communication.

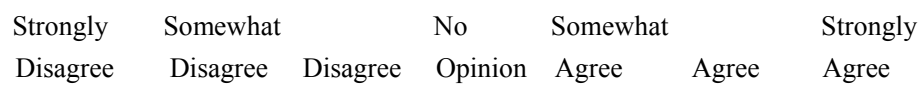

16H. An online course is an efficient means of communicating with others.

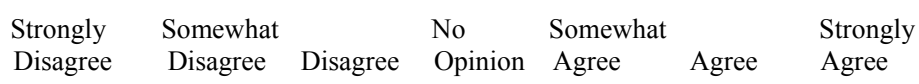

16I. I did not find the online course threatening to me.

\begin{tabular}{|c|c|c|c|c|c|}
\hline Strongly & Somewhat & & No & Somewhat & \\
\hline Disagree & Disagree & Disagree & Opinion & Agree & Agree \\
\hline
\end{tabular}

16J. I felt I got to learn a great deal about the instructor in the online course.

\begin{tabular}{|c|c|c|c|c|c|}
\hline Strongly & Somewhat & & No & Somewhat & \\
\hline Disagree & Disagree & Disagree & Opinion & Agree & Agree \\
\hline
\end{tabular}

16K. I felt I got to learn a great deal about the other students in the online course.

\begin{tabular}{|c|c|c|c|c|c|}
\hline Strongly & Somewhat & & No & Somewhat & \\
\hline Disagree & Disagree & Disagree & Opinion & Agree & Agree \\
\hline
\end{tabular}

\section{ACKNOWLEDGEMENTS}

The author of this paper is grateful to the students in the Administration and Supervision Program at Hunter College who are always willing to try new things, who provide valuable feedback, and who have made me a better teacher. 


\section{REFERENCES}

1. Galt Global Review. Education news: Virtual classrooms booming. (December 2001). $\mathrm{http}: / / \mathrm{www}$. galtglobalreview.com/education/virtual_classrooms.html

2. Phipps, R.A. and Merisotis, J. P. What's the difference: A review of contemporary research on the effectiveness of distance learning in higher education. Washington, D.C.: The Institute for Higher Education Policy, 1999. http://www.chea.org/Events/QualityAssurance/98May.html

3. Phipps, R.A., Wellman, J.V., and Merisotis, J. P. Assuring quality in distance learning: A report prepared for the Council for Higher Education Accreditation. Washington, D.C.: The Institute for Higher Education Policy, 1998.

4. Stubbs, M. Language, Schools, and Classrooms. London: Methuen, 1976.

5. Sener, J. Bringing ALN into the mainstream: NVCC case studies. In Online Education: Proceedings of the 2000 Sloan Summer Workshop on Asynchronous Learning Networks. Volume 2 in the Sloan-C series, J. Bourne and J. Moore, Editors, Needham, MA: Sloan-C Press, 2001.

6. Chickering A.W. and Gamson, A.F. Seven principles for good practice in undergraduate education. Racine, WI: The Johnson Foundation, Inc., 1987.

7. Kumari, D.S. Connecting graduate students to virtual guests through asynchronous discussions: analysis of an experience. Journal of Asynchronous Learning Networks, 5(2), 2001. http://www.aln.org/alnweb/journal/Vol5_issue2/Kumari/Kumari.htm

8. Fulford, C.P. and Zhang, S. Perceptions of interaction: The critical predictor in distance education. The American Journal of Distance Education 7(3): 8-21,1993.

9. Kearsley, G. The nature and value of interaction in distance education. Distance Education Symposium 3: Instruction. University Park, PA: American Center for the Study of Distance Education, 1995.

10. Sherry, L. Issues in distance learning. International Journal of Distance Education, 1(4), 337-365, 1996.

11. Picciano, A.G. Distance Learning: Making Connections across Virtual Space and Time. Upper Saddle River, NJ: Prentice-Hall, 2001.

12. Picciano, A.G. Developing an asynchronous course model at a large, urban university. Journal of $\begin{array}{llll}\text { Asynchronous } & \text { Learning } & \text { Networks, } & 2(1),\end{array}$ http://www.aln.org/alnweb/journal/vol2_issue1/picciano.htm

13. Shea, P., Fredericksen, E., Pickett, A., Pelz, W., and Swan, K. Measures of learning effectiveness in the SUNY Learning Network. In Online Education: Proceedings of the 2000 Sloan Summer Workshop on Asynchronous Learning Networks. Volume 2 in the Sloan-C series, J. Bourne and J. Moore, Editors, Needham, MA: Sloan-C Press, 2001.

14. Hartman, J. L. and Truman-Davis, B. Factors related to the satisfaction of faculty teaching online courses at the University of Central Florida. In Online Education: Proceedings of the 2000 Sloan Summer Workshop on Asynchronous Learning Networks. Volume 2 in the Sloan-C series, J. Bourne and J. Moore, Editors, Needham, MA: Sloan-C Press, 2001.

15. Dziuban, C. and Moskal, P. Emerging research issues in distributed learning. Orlando, FL: Paper delivered at the 7th Sloan-C International Conference on Asynchronous Learning Networks, 2001.

16. Ruberg, L. F., Taylor, C.D., and Moore, D.M. Student participation and interaction on-line: A case study of two college classes: Freshman Writing and Plant Science Lab. International Journal of Educational Telecommunications, 2(1), 69-92, 1996.

17. Sproull, L.S. and Kiesler, S. Connections: New Ways of Working in the Networked Organization. Cambridge, MA: MIT, 1991.

18. Mackay, W.E. Diversity in the Use of Electronic Mail: A preliminary inquiry." ACM Transactions on Office Information Systems, 6(4), 380-397, 1989.

19. Varian, H. "The Information Economy." Scientific American, 273(3), 200-202, 1995.

20. Beaudoin, M. Learning or lurking? Tracking the 'invisible' online student. Orlando, FL: Paper delivered at the 7th Sloan-C International Conference on Asynchronous Learning Networks, 2001. 
21. Mehrabian, A. Some referents and measures of nonverbal behavior. Behavior Research Methods and Instrumentation, 1(6), 205-207, 1969.

22. Short, J., Williams, E. and Christie, B. The Social Psychology of Telecommunications. London: John Wiley and Sons, 1976.

23. Lombard, M. and Ditton, T. At the heart of it all: The concept of presence. Journal of Computer Mediated Communications, 3(2), 1997. http:/www.ascusc.org/jcmc/vol3/issue2/lombard.html

24. Tammelin, M. From telepresence to social presence: The role of presence in a network-based learning environment. In Aspects of Media Education: Strategic Imperatives in the Information Age. Tella, S., Editor. Media Education Centre. Department of Teacher Education. University of Helsinki. Media Education Publications 8, 1998.

25. Moore, G. Sharing faces, places, and spaces: The Ontario Telepresence Project Field Studies. In Video- Mediated Communication. Finn, K. E., Sellen, A. J. and Wilbur, S. B., Editors. Mahwah, NJ: Lawrence Erlbaum, 301-321, 1997.

26. Buxton, W. A. S. Telepresence: Integrating shared task and person spaces. In Readings in Groupware and Computer-Supported Cooperative Work. Baecker, R. M. Editors. San Mateo, CA: Morgan Kaufmann, 816-822, 1993.

27. Biocca, F. Presence. Presentation at a workshop on Cognitive Issues in Virtual Reality, VR ' 95 Conference and Expo, San Jose, CA, 1995.

28. Rourke, L., Anderson, T. Garrison, D.R, and Archer, W. Assessing social presence in asynchronous text-based computer conferencing. Journal of Distance Education/Revue de l'enseignement à distance, 2001. http://cade.athabascau.ca/vol14.2/rourke et al.html

29. Keegan, D. Foundations of Distance Education (3rd ed.). London: Routledge, 1996.

30. Healy, P. Harvard figures show most of its grades are A's or B's. The Boston Globe, p. B6, (November 21, 2001).

31. Hanson, D., Maushak, N.J., Schlosser, C.A., Anderson, M.L., Sorenson, C., and Simonson, M. Distance education: Review of the literature, 2nd Edition. Washington, D.C.: Association For Educational Communications and Technology, 1997.

32. Tu, Chih-Hsiung. How Chinese perceive social presence: An examination of interaction in an online learning environment. Educational Media International; v38 n1 p. 45-60, 2001.

\section{ABOUT THE AUTHOR}

Dr. Picciano is a professor in the Education Administration and Supervision Program in the School of Education at Hunter College. His teaching specializations include educational technology, organization theory, and research methods.

He has been involved with a number of major grants from the National Science Foundation, the Alfred P. Sloan Foundation, the US Department of Education, and IBM. He has collaborated with The American Social History Project and Center for Media and Learning at CUNY on a number of instructional multimedia projects dealing with subjects such as Irish immigration in the $1850 \mathrm{~s}$, women's rights and labor issues at the turn of the century, and school integration in the 1950s. One of these programs, The Five Points: A Multimedia Experience in Social History, was selected to be part of a New Learning Technologies Exhibit, held in San Diego in 1992. His present research interests are centered on distance learning technologies including asynchronous learning using Internet tools and media distribution systems.

Dr. Picciano has served as a consultant for a variety of public and private organizations including the New York City Board of Education, the New York State Department of Education, Commission on Higher 
Education/Middle States Association of Colleges and Universities, the US Coast Guard, and CITICORP. $\mathrm{He}$ is the author of four books on education and technology including Educational Leadership and Planning for Technology, 3rd Edition (Prentice-Hall, 2002) and Distance Learning: Making Connections Across Virtual Space and Time (Prentice-Hall, 2001). His articles on educational technology have appeared in journals such as the Journal of Asynchronous Learning Networks, Journal of Educational Multimedia and Hypermedia, Computers in the Schools, The Urban Review, Equity and Choice, and EDUCOM Review. 